\title{
Pan-Canadian opioid strategy to be released amid brouhaha
}

I $t$ begs the question: Does the right hand know what the left hand is doing? While Federal Health Minister Leona Aglukkaq has been pointing fingers at doctors for over-prescribing opioids and calling on the provinces to cede jurisdiction if they're not up to the task of policing overprescribers, Health Canada has provided financial support for the development of a pan-Canadian strategy to combat prescription drug abuse, including over-prescribing.

The irony is not lost on observers such as Doug Spitzig, manager of the prescription review program at the College of Physicians and Surgeons of Saskatchewan and a member of the National Advisory Council on Prescription Drug Misuse (NACPDM), which is crafting the strategy, expected to be released in January.

Over the course of the brouhaha over oxycodone abuse and over-prescribing, "they're not even mentioning that [strategy] at all," notes Spitzig, who wonders whether Health Canada has lost its focus on the file.

Although it's not uncommon for a large bureaucracy to get bogged down in semantics and lose track of projects they have in the pipeline, the lack of vocal support from Health Canada for the pan-Canadian strategy may ultimately prove detrimental, Spitzig says. “They've got to take a look at how can they support this, because you have all the specialists from across the country that have developed this strategy."

Canada currently ranks as the second largest consumer of prescription opioids in the world behind the United States, while deaths from oxycodone increased by $416 \%$ between 1999 and 2004. But the Canadian Centre on Substance Abuse (CCSA) says the precise scale of the problem is unknown due to a lack of national data on substance abuse, addiction and related deaths (www.ccsa.ca/2012\%20CCSA\%20

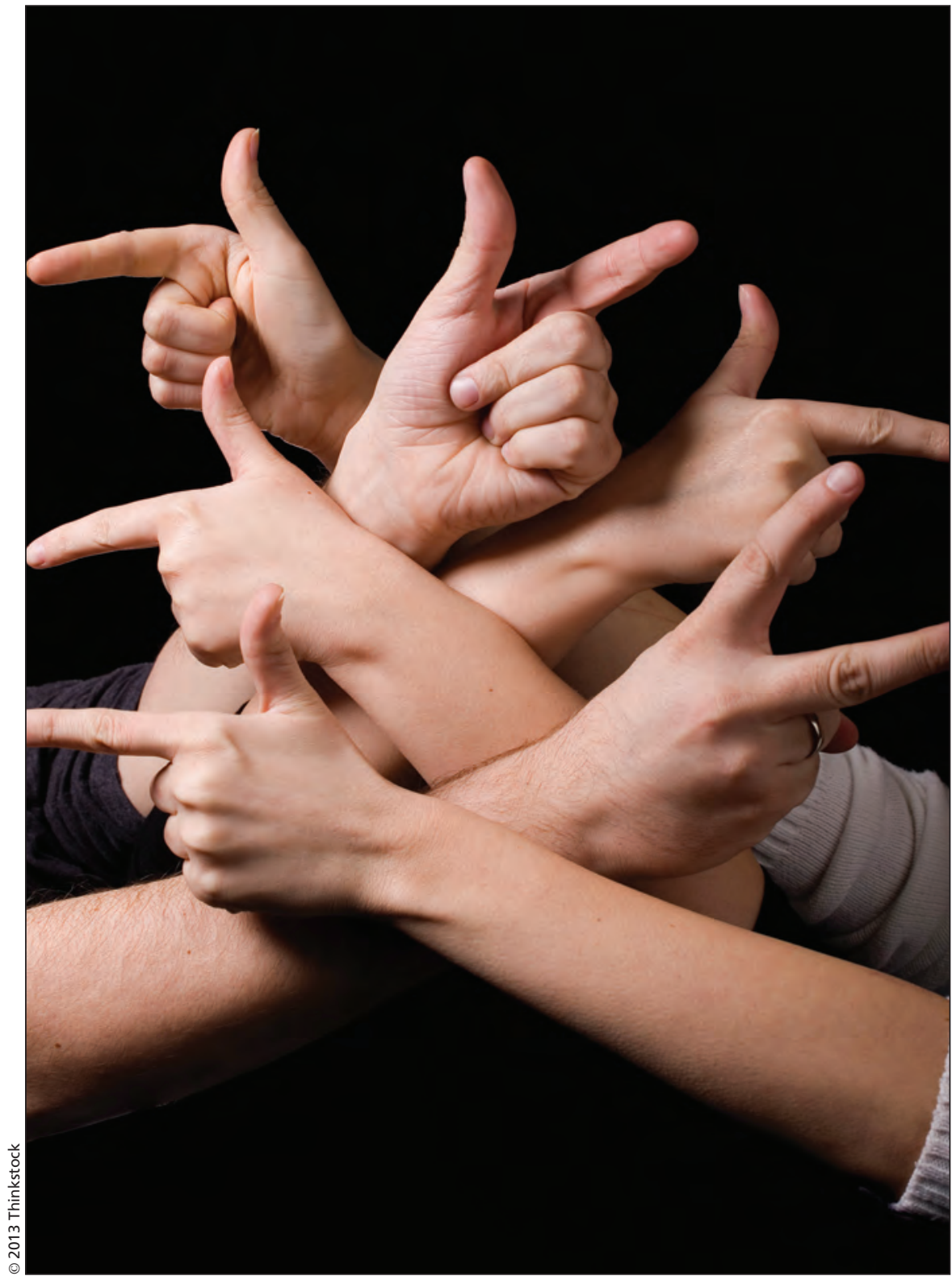

Health Canada says it hasn't forgotten the pan-Canadian opioid strategy during the ongoing intergovernmental brouhaha over whether generic oxycodone should be prohibited as part of a bid to curb opioid abuse and over-prescribing.

Documents/PDM-Press-Release-2012 -June-11-en.pdf).

In a bid to redress that deficiency, the federally funded association last year proposed the development of the pan-Canadian approach on prescription drug misuse during a meeting of stake- holders and medical experts in Ottawa, Ontario.

There are now 46 members on the national advisory council, including pain and addiction specialists, researchers, pharmacists, medical professionals, regulators, law enforcement 
officials and industry leaders. They propose to release a strategy early this year that focuses on five areas: education, prevention, treatment, enforcement and monitoring of patients and physicians.

Spitzig says bringing all the provinces and territories up to speed with prescription monitoring programs that can communicate with each other electronically will be critical. Only a handful of provinces now have such a system in place, he notes. "But it's not as if you'll have one agency in Ottawa that just looks at a computer and just runs numbers. You need the various provincial organizations with monitoring programs, where they are working in the trenches so to speak."

For its part, Health Canada says it hasn't forgotten the strategy during the ongoing intergovernmental brouhaha over whether generic oxycodone should be prohibited as part of a bid to curb opioid abuse and over-prescribing.

"It's not forgotten ... [ellipsis included] it's just not our lead," Sean Upton, a departmental spokesman, writes in an email. "Health Canada officials and other government officials are participating but the document itself will come from the CCSA and I don't think there is much to say about it until it comes out."

Aglukkaq made little mention of the strategy during the recent debate because "it hasn't been released yet," Cailin Rodgers, the minister's press secretary, writes in an email. "Health Canada is participating, but it is CCSAled. We look forward to the release of their strategy."

Health Canada may be not expressing vocal support for the pan-Canadian strategy because it may fear having its hands tied by certain recommendations, surmises Robert Eves, CCSA director of partnerships and priorities. "They are there as advisors currently and trying to look at the strategy moving forward, where do they fit into it and what pieces would they see themselves assuming the leadership on."

But Eves expects the federal government will eventually accept that it has a responsibility and a role to play in efforts to contain opioid abuse.

"The first part of what they're saying, which is that they aren't the leader, is true, and as our CEO is fond of saying and I do agree that "not all roads lead to the federal government.' So within the strategy they will be a part of it and they will be committed to being a part of it - but they're not leading it," Eves says. "They may take leadership on specific pieces but they aren't taking leadership on the strategy as a whole. That still falls to the national advisory council to shepherd and implement the strategy as it moves forward."

Eves adds that Spitzig and others who are concerned about Health Canada's failure to provide vocal support for the strategy are mistakenly assuming that the department isn't firmly behind the initiative.

"It may be that this is a very large issue and it has yet to see a coordinated balance of action across the country including Health Canada. But that's all of the partners involved, because one of the things that has drawn all of these people to the table like Doug is that they really do want to do something about this," he says. "However, the platform to do it from on a national level hasn't existed until this point so it can feel in early phases like things are a bit disconnected." Adam Miller, CMAJ

CMAJ 2013. DOI:10.1503/cmaj.109-4379 